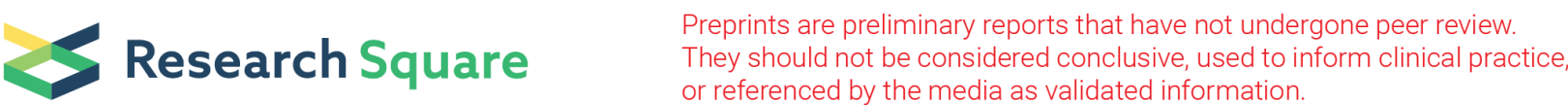

\section{Quantitative Health Risk Assessment of Wastewater Treatment Plant Worker Exposed to Staphylococcus Aureus Bioaerosol During Warm and Cold Periods: Disease Burden and Sensitivity Analysis}

\section{Jia-xin Ma}

China University of Geosciences

Bei-bei Cui

China University of Geosciences

Man-li Liu

Hubei Water Resources Technical College

Jie Yuan

China University of Geosciences

Cheng Yan ( $\nabla$ cheng_yan@cug.edu.cn )

China University of Geosciences

\section{Research Article}

Keywords: Sensitivity analysis, Quantitative microbial risk assessment, Monte Carlo simulation, Personal protective equipment, Disease burden

Posted Date: November 30th, 2021

DOI: https://doi.org/10.21203/rs.3.rs-1070258/v1

License: (c) (i) This work is licensed under a Creative Commons Attribution 4.0 International License.

Read Full License 


\section{Abstract}

Biological treatment in wastewater treatment plants (WWTPs) releases high amounts of bioaerosols carrying a variety of pathogens. Quantitative microbial risk assessment (QMRA) is a framework prevalently intended for the quantitative estimation of health risks for occupational exposure scenarios (e.g. in WWTPs). However, the quantitative contributions of health-risk-estimate inputted variable parameters remain ambiguous. Therefore, this research aimed to study the disease burden of workers exposed to Staphylococcus aureus bioaerosol during warm and cold periods and to strictly quantify the contributions of the inputted parameters of disease burden by sensitivity analysis based on Monte Carlo simulation. The results showed that the disease health risk burden in the warm period was higher than in the cold period, disease health risk burden in the rotating-disc aeration mode was regularly higher than in the microporous aeration mode. The disease health risk burden of the workers with personal protective equipment (PPE) almost all satisfied the WHO benchmark ( $\leq 10 \mathrm{E}-6$ DALYs pppy), and was consistently lower by one or two orders of magnitude than the workers without PPE in both warm and cold periods. Referring to the sensitivity analysis, exposure concentration and aerosol ingestion rate were the most and second predominant factor for the estimated risk in all exposure scenarios, respectively. The sensitivity of the removal fraction by employing PPE ranked third in the contribution to disease health risk burden. In addition, no remarkable differences were revealed in the sensitivity percentage ratio between warm and cold periods. This research can deepen the understanding of the QMRA framework and promote the development of sensitivity analysis, especially under various meteorological conditions (warm and cold periods).

\section{Introduction}

Biological treatment is the most predominant treatment process in wastewater treatment plants (WWTPs), and it is one of the main sources of bioaerosols (Kowalski et al., 2017; Thakur et al., 2018; Han et al., 2019; Han et al., 2020a). Large numbers of microorganisms exist in wastewater and sludge (Uhrbrand et al., 2017; Kozajda et al., 2019). The indispensable oxygen supply (i.e., microporous and mechanical aeration) during the biological treatment process results in the production and release of high amounts of bioaerosols carrying a variety of pathogens (Han et al., 2019; Han et al., 2020b; Tian et al., 2020). Workers in WWTPs encounter a potential health risk from these pathogenic bioaerosols mainly through inhalation (Upadhyay et al., 2013; Masclaux et al., 2014; Han et al., 2020a). Therefore, bioaerosol risk characteristics and measures to reduce risk in WWTPs have attracted increasing attention.

At present, no dedicated risk control standards or strategies are available for bioaerosols in WWTPs because unquantifiable variable parameters are involved in the health risk assessment process. According to prior studies, the health risks of workers in WWTPs can be significantly reduced by equipping them with personal protective equipment (PPE) (Teixeira et al., 2013; Haas et al., 2017). In addition, bioaerosol concentrations relating to health risks in WWTPs can be influenced by meteorological parameters in different seasons (such as temperature, relative humidity, and solar illumination) (Zhai et al., 2018; Singh et al., 2020) and aeration modes (mechanical and microporous 
aeration modes) (Sánchez-Monedero et al., 2008; Han et al., 2019). Therefore, sensitivity analysis was used to quantify the contributions of inputted aforementioned variable parameters to health risk assessment and then determine the most influential parameter (Saltelli et al., 2019; Dean and Mitchell, 2020). Meanwhile, Monte Carlo simulation was used to perform multiple random samplings and iterative computations for sensitivity analysis (de Matos Nascimento et al., 2020; Xu et al., 2020).

Quantitative microbial risk assessment (QMRA) is a framework intended for the quantitative estimation of health risks in occupational exposure scenarios (Haas, 2015; Haas et al., 2017; Seis et al., 2020), and was carried out following: (i) hazard identification, (ii) exposure assessment, (iii) dose-response assessment, and (iv) risk characterization (Shi et al., 2018). Dose-response assessment is typically carried out through the exponential dose-response model, while risk characterization is performed to assess the health risk by disease burden (Haas, 2015; Esfahanian et al., 2019). Disease burden is evaluated by the acceptable disability-adjusted life years (DALYs), as proposed by World Health Organization, and is the most authoritative and widely-used health risk benchmark ( $\leq 10^{-6}$ DALYs per person per year (pppy)) (WHO 2008; Shi et al., 2018).

Therefore, based on our previous research, we aimed to study the disease burden of workers exposed to Staphylococcus aureus bioaerosol by using the exponential dose-response model in a WWTP under mechanical aeration and microporous aeration modes during warm and cold periods. Then, the contributions of the inputted parameters of disease burden were strictly quantified to determine the most influential variable parameter by Monte Carlo simulation. This research can further deepen the understanding of the dynamic uncertainty analysis under two extremely different meteorological conditions (warm and cold periods). The findings can also contribute effort to the establishment of mitigation measures and control strategies for the management of public health risks including exposure to bioaerosols in local utilities.

\section{Materials And Methods}

\subsection{WWTP description}

This study was performed at a WWTP, which was built in 2014, located in China. The collected domestic wastewater is distributed into the WWTP by a series of variable-frequency pump stations. The WWTP maintains two independently operated parallel phases and is equipped with a rotating-disc aeration tank (mechanical aeration mode) for Phase I and a microporous aeration tank (microporous aeration mode) for Phase II (Fig. 1). The treatment capacity of Phases I and II is 50,000 tons per day. 
Table 1

Sampling log $\left(\mathrm{CFU} \cdot \mathrm{m}^{-3}\right)$

\begin{tabular}{|llll|}
\hline Periods & Sampling site & $\begin{array}{l}\text { Sampling time } \\
\text { (minute) }\end{array}$ & Exposure concentration (CFU·m ${ }^{-3}$ ) \\
\hline $\begin{array}{l}\text { Warm } \\
\text { period }\end{array}$ & $\begin{array}{l}\text { Rotating-disc } \\
\text { aeration tank }\end{array}$ & 5 & $\begin{array}{l}\text { Lognormal distribution (Mean = 4840.49; Std. } \\
\text { Dev. }=3015.88)\end{array}$ \\
\cline { 2 - 4 } & $\begin{array}{l}\text { Microporous } \\
\text { aeration tank }\end{array}$ & 5 & $\begin{array}{l}\text { Lognormal distribution (Mean = 270.52; Std. } \\
\text { Dev. }=168.34)\end{array}$ \\
$\begin{array}{l}\text { Cold } \\
\text { period }\end{array}$ & $\begin{array}{l}\text { Rotating-disc } \\
\text { aeration tank }\end{array}$ & 5 & $\begin{array}{l}\text { Lognormal distribution (Mean }=723.04 ; \text { Std. } \\
\text { Dev. }=437.66)\end{array}$ \\
\cline { 2 - 4 } & $\begin{array}{l}\text { Microporous } \\
\text { aeration tank }\end{array}$ & $\begin{array}{l}\text { Lognormal distribution (Mean }=118.53 ; \text { Std. } \\
\text { Dev. }=66.52)\end{array}$ \\
\hline
\end{tabular}

\subsection{Sampling and analysis}

\subsubsection{Sampling procedure}

An Anderson six-stage impactor was used to collect Staphylococcus aureus bioaerosol samples with different size ranges (Byeon et al., 2008; Kowalski et al., 2017). The sampling campaign was conducted on 2020 Sept. 20th, 2020 Sept. 27th, 2020 Dec. 7th, and 2020 Dec. 16th. Samples were taken in the rotating-disc aeration tank and microporous aeration tank at the same time, and each sampling was repeated thrice. The sampling site was located in the middle of the corridor of each aeration tank (Fig. 1). At each sampling site, the Anderson six-stage impactor was mounted at $1.5 \mathrm{~m}$ above the ground level of the corridor, and the impactor was operated at a flow rate of $28.3 \mathrm{~L} / \mathrm{min}$ (Hung et al., 2010; Kowalski et al., 2017). The impactor was sterilized with $75 \%$ alcohol pads before and after each sampling to prevent contamination. In addition, sampling conditions, such as temperature, relative humidity, and solar illumination were recorded (Supplementary Material Table 1). The temperature for warm and cold period was divided as $25-35^{\circ} \mathrm{C}$ and $5-15^{\circ} \mathrm{C}$, respectively (Supplementary Material Table 1). All samples were transported to the lab immediately in a cold box and analyzed within 48 hours (Pascual et al., 2003).

\subsubsection{Bioaerosol analysis}

The media used in the Anderson six-stage impactor for sampling airborne Staphylococcus aureus was egg-yolk mannitol salt agar base (Qingdao Hope Bio-Technology Co., Ltd.). The preparation and cultivating methods followed standard procedures and previous publications (Pascual et al., 2003; Grzyb et al., 2019). The samples were enumerated as colony-forming unit (CFU) by using an automatic colony enumeration instrument (HICC-B, Wanshen Inc., Hangzhou, China). Only plates containing colonies less than 300 were counted to prevent colony masking due to overloading (Hung et al., 2010). The actual number of colonies in each sample was corrected by the positive-hole method (Andersen, 1958; Carducci et al., 2018; Han et al., 2020b). All the results of bioaerosol concentrations were expressed as the number of CFU per cubic meter of air (CFU m ${ }^{-3}$ ) (Yang et al., 2019). 
Table 2

Calculation parameters of quantitative microbial risk assessment

\begin{tabular}{|c|c|c|c|c|}
\hline Items & Description & Units & Values & References \\
\hline C & Exposure concentration & $\mathrm{CFU} \cdot \mathrm{m}^{-3}$ & Table 1 & - \\
\hline \multirow[t]{2}{*}{$B R$} & Breathing rate & $m^{3} \cdot d^{-1}$ & $\begin{array}{l}\text { Uniform } \\
\text { distribution } \\
\text { (Min = 7.2; }\end{array}$ & Wang et al., 2018 \\
\hline & & & $\operatorname{Max}=15.7)$ & \\
\hline \multirow[t]{2}{*}{$A G$} & Aerosol ingestion rate & $\%$ & $\begin{array}{l}\text { Uniform } \\
\text { distribution } \\
\text { (Min = 10; }\end{array}$ & Jahne et al., 2015 \\
\hline & & & Max $=50)$ & \\
\hline \multirow[t]{2}{*}{$T$} & Exposure time & $h \cdot d^{-1}$ & $\begin{array}{l}\text { Uniform } \\
\text { distribution } \\
\text { (Min = 0.50; }\end{array}$ & Field investigation \\
\hline & & & $\operatorname{Max}=1)$ & \\
\hline$P_{i}(d)$ & $\begin{array}{l}\text { Exponential dose-response } \\
\text { model }\end{array}$ & Unitless & $k=8.05 E-08$ & Esfahanian et al., 2019 \\
\hline \multirow[t]{2}{*}{$F P P E$} & $\begin{array}{l}\text { Removal fraction by employing } \\
\text { personal protective equipment }\end{array}$ & Unitless & $\begin{array}{l}\text { Uniform } \\
\text { distribution } \\
\text { (Min = 0.95; }\end{array}$ & $\begin{array}{l}\text { Rosenstock, 1995; } \\
\text { Cyprowski et al., 2008; } \\
\text { Mark et al., } 2020\end{array}$ \\
\hline & & & $\operatorname{Max}=0.99)$ & \\
\hline$n$ & Exposure frequency & $d \cdot y^{2}{ }^{-1}$ & 250 & Field investigation \\
\hline$P_{\text {ill/inf }}$ & Prevalence & Unitless & 1 & Busgang et al., 2018 \\
\hline$H B$ & Health burden & DALYs.case ${ }^{-1}$ & $\mathrm{HB}=0.0026$ & Havelaar et al., 2012 \\
\hline
\end{tabular}

\subsection{QMRA framework}

QMRA was carried out following the classical four-step framework (Haas, 2015; Haas et al., 2017). All details and explanations were showed in the Table 2 and Supplementary Material. In fact, the Staphylococcus aureus were popularly confirmed as the most frequently detected, widely distributed, and extensively studied potential hazard in most bioaerosol samples (Kozajda et al., 2019). Therefore, for hazard identification, the indicator pathogen of concern in this study was Staphylococcus aureus bioaerosol emitted from the two aeration tanks.

The workers in this study were equipped with a wide range of models of PPE, including N-95 and N-99, as well as other types which efficacy were presumed between $\mathrm{N}-95$ and $\mathrm{N}-99$. The dose of bioaerosol inhaled was analyzed according to the literatures (Rosenstock, 1995; Cyprowski et al., 2008; Mark et al., 2020). 
The exponential dose-response model was utilized for the Staphylococcus aureus bioaerosol (Esfahanian et al., 2019). Hereby, the daily infection risk and annual infection risk, as well as disease burden, were estimated.

\subsection{Monte Carlo simulation and sensitivity analysis}

All inputted variable parameters (exposure concentration, aerosol ingestion rate, removal fraction by employing PPE (FPPE), exposure time, and breathing rate) were randomly selected from their corresponding probability distributions (Table 1 and 2). Then, the disease burden was calculated with 10,000 iterations (Supplementary Material Eq. (5)). The sensitivity analysis was used to quantify the contributions of all QMRA inputted variable parameters to the uncertainty in health risk output (the disease burden) (Saltelli, 2002; Dias et al., 2019; Saltelli et al., 2019). The quantification contribution (the sensitivity partitioning coefficient) was calculated by using the Spearman rank correlation coefficient in Oracle Crystal Ball (Dean and Mitchell, 2020).

\section{Results And Discussion}

The mean concentration and standard deviation of exposure bioaerosol under mechanical and microporous aeration mode during warm and cold periods were reported in the Table 1.

\subsection{Characterization of disease health risk burden}

Box plot in the Fig. 2 demonstrates the disease burden with the first and third quartiles (25th and 75th percentiles), the mean value (general condition), the 2.5 th percentile (optimistic estimate at the best situation), and the 97.5th percentile (conservative estimate at the worst situation). They were all compared with the World Health Organization (WHO) benchmark ( $\leq 10 \mathrm{E}-6$ DALYs pppy).

The disease health risk burden of the workers (with or without PPE) in the warm period was constantly one order of magnitude higher than that in cold period under all estimate situations. This result can be attributed to the higher bioaerosol concentrations in the warm period (Table 1). Niazi et al. (2015) and Singh et al. (2020) stated a similar result, that is, the average concentration of bacterial bioaerosols in summer (warm period) was considerably higher than that in winter (cold period) for the aeration tank in a WWTP. In general, the high temperature and relative humidity in warm period during the sampling campaign of this research (Supplementary Material Table 1) supported the survival of bioaerosols (Dehghani et al., 2018; Han et al., 2018, 2019; Singh et al., 2020). Besides, all disease health risk burden in the rotating-disc aeration mode was regularly consistently higher by one order of magnitude than it in the microporous aeration mode. Literature reveals that the mechanical aeration mode differs from the microporous aeration mode, exerts strong shear forces, and constantly generates a high concentration of bioaerosols (Sánchez-Monedero et al., 2008; Li et al., 2016; Han et al., 2019; Burdsall et al., 2020). In the rotating-disc aeration mode, the higher bioaerosol concentration contributed to the higher exposure dose and bioaerosol-relative health risk calculated in the QMRA (Dean and Mitchell, 2020; Han et al., 2020b). Therefore, reducing bioaerosol emission and switching of mechanical aeration mode to microporous 
aeration mode are promising strategies (Sánchez-Monedero et al., 2008; Fathi et al., 2017; Han et al., 2019; Burdsall et al., 2020).

For workers without PPE, the disease health risk burden in rotating-disc aeration tank in warm period exceeded the WHO benchmark for all condition; the disease health risk burden in cold period under the optimistic estimate satisfied the WHO benchmark. The disease health risk burden in microporous aeration tank in warm period under general condition and in cold period under the conservative estimate were both on the same order of magnitude as the benchmark. The disease health risk burden of the workers with PPE all satisfied the WHO benchmark in the two aeration tanks excepting for rotating-disc aeration tank in warm period at the worst situation, and was consistently lower by one or two orders of magnitude than the workers without PPE in both warm and cold periods. Therefore, disease health risk burden can be significantly mitigated by one or two orders of magnitude by equipping workers with PPE.

\subsection{Sensitivity analysis of the results of disease health risk burden}

Figure 3 displays the sensitivity partitioning coefficient of parameters in the two aeration tanks in warm and cold periods. Fig. 4 demonstrates the sensitivity percentage ratio of each sensitivity parameter in each exposure scenario.

The sensitivity analysis indicated that the exposure concentration and aerosol ingestion rate were the most and second predominant factor for the estimated risk in all exposure scenarios, respectively (Fig. 3). The sensitivity partitioning coefficient of exposure concentration was 1.17 to 1.35 times the value of the aerosol ingestion rate (Fig. 3). The degree of dispersion (standard deviation) of bioaerosol concentration was more than $50 \%$ of its mean value in all exposure scenarios. This led to the highest sensitivity ranking of exposure concentration. Therefore, decreasing the exposure concentration is one of the most significant methods to lessen the disease health risk burden in theory. Besides, controlling the aerosol ingestion rate, which is highly affected by breathing pattern, is an effective way to mitigate the disease health risk burden (Stuart, 1984; Warren et al., 1988; Lim et al., 2015). Literature reported that nasal breathers had higher infection risks than habitual oral breathers by about two orders of magnitude (Shi et al., 2018). Therefore, health risk mitigation may be achieved by effective oral breathing.

However, the sensitivity of the FPPE ranked third in the contribution to disease health risk burden. The sensitivity partitioning coefficient of the FPPE was 0.03 lower (by absolute value) to aerosol ingestion rate in all exposure scenarios and they showed almost the same sensitivity partitioning coefficients (by absolute value) and sensitivity percentage ratios (Figs. 3 and $4 \mathrm{~b}$ ). This result further demonstrates that the wearing of PPE can largely reduce the risk (Haas et al., 2017; Carducci et al., 2018), and proves that it is another effective way to mitigate the disease health risk burden.

In addition, breathing rate and exposure time showed an alternating regularity in two periods. In rotatingdisc aeration tank, the breathing rate ranked ahead the exposure time in warm period while the exposure 
time ranked ahead the breathing rate in cold period. And it was on the contrary in microporous aeration tank.

Referring to the sensitivity percentage ratio in one particular aeration mode, no remarkable differences were revealed between warm and cold periods (Fig. 4). This finding may be due to the same inputted values and distribution patterns of these sensitivity parameters, except the exposure concentration (Table 1). Hence, the disease health risk burdens in warm and cold periods are equally important and thus deserve correspond research attention.

\section{Conclusion}

The disease health risk burden of workers exposed to the bioaerosol in the warm period was constantly one order of magnitude higher than that in cold period, the disease health risk burden in the rotating-disc aeration mode was regularly consistently higher by one order of magnitude than it in the microporous aeration mode.

Furthermore, the disease health risk burden of the workers with PPE all satisfied the WHO benchmark excepting for rotating-disc aeration tank in warm period at the worst situation, and was consistently lower by one or two orders of magnitude than the workers without PPE in both warm and cold periods. For workers without PPE, the disease burden values in rotating-disc aeration tank in warm period exceeded the WHO benchmark for all condition; the burden in cold period under the optimistic estimate satisfied the WHO benchmark. The burden in microporous aeration tank in warm period under general condition and in cold period under the conservative estimate were both on the same order of magnitude as the benchmark.

The sensitivity analysis indicated that the exposure concentration and aerosol ingestion rate were the most and second predominant factor for the estimated risk in all exposure scenarios, respectively. However, the sensitivity of the FPPE ranked third in the contribution to disease health risk burden. Therefore, decreasing the exposure concentration is the most preferred in theory to lessen the health risk; effective oral breathing and equipping personal protective equipment are also feasible methods to reduce the risk. In addition, no notable differences were discovered in the sensitivity percentage ratio between warm and cold periods, revealing that seasonal variation equally contributed to the health risk.

This research systematically further delivered novel data on the sensitivity analysis of quantitative health risk assessment framework in one WWTP for comparing exposure to bioaerosols in warm and cold periods. This sensitivity analysis study can provide a theoretical basis for follow-up research on the mitigation measures and then assist local utilities understanding control strategies for bioaerosol exposure.

\section{Declarations}

\section{Ethics approval and consent to participate}




\section{Consent for publication}

Not applicable.

\section{Availability of data and materials}

All data generated or analyzed during this study are included in this published article and its supplementary information files.

\section{Competing interests}

The authors declare that they have no competing interests.

\section{Funding}

We declare that the sources of funding for this research include the National Natural Science Foundation of China and the Fundamental Research Funds for the Central Universities, China University of Geosciences (Wuhan). The funding bodies only provide financial support in the design of the study and collection, analysis, and interpretation of data and in writing the manuscript.

\section{Authors' contributions}

Conceptualization: [CY, JM]; Methodology: [CY, JM, BC, ML]; Formal analysis and investigation: [CY, JM, $B C, M L, J Y]$; Writing - original draft preparation: [CY, JM, BC]; Writing - review and editing: [CY, JM, $B C, M L$, JY]; Funding acquisition: [CY]; Resources: [CY]; Supervision: [CY].

\section{Acknowledgments}

This study was sponsored by the National Natural Science Foundation of China (51608497) and the Fundamental Research Funds for the Central Universities, China University of Geosciences (Wuhan) (CUGGC07).

\section{References}

1. Andersen AA (1958) New sampler for the collection, sizing, and enumeration of viable airborne particles. Bacteriol 76(5):471-484 
2. Burdsall AC, Xing Y, Cooper CW, Harper WF (2020) Bioaerosol emissions from activated sludge basins: characterization, release, and attenuation. Sci Total Environ 753:141852

3. Byeon JH, Park CW, Yoon KY, Park JH, Hwang J (2008) Size distribution of total airborne particles and bioaerosols in a municipal composting facility. Bioresour Technol 99(11):5150-5154

4. Carducci A, Donzelli G, Cioni L, Federigi I, Lombardi R, Verani M (2018) Quantitative microbial risk assessment for workers exposed to bioaerosol in wastewater treatment plants aimed at the choice and setup of safety measures. Int J Env Res Pub He 15(7):1490-1496

5. Cyprowski M, Sowiak M, Soroka PM, Buczyrńska A, Kozajda A, Szadkowska-Stańczyk I (2008) Assessment of occupational exposure to fungal aerosols in wastewater treatment plants. Med $\mathrm{Pr}$ 59(5):365-371

6. de Matos Nascimento A, de Paula V, Costa Carneiro J, Otenio M (2020) Quantitative microbial risk assessment of occupational and public risks associated with bioaerosols generated during the application of dairy cattle wastewater as biofertilizer. Sci Total Environ 745:140711

7. Dean K, Mitchell J (2020) Reverse QMRA for pseudomonas aeruginosa in premise plumbing to inform risk management. J Environ Eng 146(3):04019120

8. Dehghani M, Sorooshian A, Ghorbani M, Fazlzadeh M, Miri M, Badiee P, Delikhoon M (2018) Seasonal variation in culturable bioaerosols in a wastewater treatment plant. Int $\mathrm{J}$ Aerosol Air Qual Res 18(11):2826-2839

9. Dias E, Ebdon J, Taylor H (2019) Microbial risk analysis estimating the concentration of viral pathogens and indicator organisms in the final effluent of wastewater treatment processes using stochastic modelling. Microbial Risk Anal 11:47-56

10. Esfahanian E, Adhikari U, Dolan K, Mitchell J (2019) Construction of a new Dose-Response model for Staphylococcus aureus considering growth and decay kinetics on skin. Pathogens 8(4):253-259

11. Fathi S, Hajizadeh Y, Nikaeen M, Gorbani M (2017) Assessment of microbial aerosol emissions in an urban wastewater treatment plant operated with activated sludge process. Aerobiologia (Bologna) 33:507-515

12. Grzyb J, Lenart-Boroń A (2019) Bacterial bioaerosol concentration and size distribution in the selected animal premises in a zoological garden. Aerobiologia 35(2):253-268

13. Haas CN (2015) Microbial dose response modeling: past, present, and future. Environ Sci Technol 49(3):1245-1259

14. Haas CN, Rycroft T, Bibby K, Casson L (2017) Risks from ebolavirus discharge from hospitals to sewer workers. Water Environ Res 89(4):357-368

15. Han Y, Wang Y, Li L, Xu G, Liu J, Yang K (2018) Bacterial population and chemicals in bioaerosols from indoor environment: sludge dewatering houses in nine municipal wastewater treatment plants. Sci Total Environ 618:469-478

16. Han Y, Yang K, Yang T, Zhang M, Li L (2019) Bioaerosols emission and exposure risk of a wastewater treatment plant with A2O treatment process. Ecotox Environ Safe 169:161-168 
17. Han Y, Yang T, Xu G, Li L, Liu J (2020a) Characteristics and interactions of bioaerosol microorganisms from wastewater treatment plants. J Hazard Mater 391:122256

18. Han Y, Yang T, Han C, Li L, Liu J (2020b) Study of the generation and diffusion of bioaerosol under two aeration conditions. Environ Pollut 267:115571

19. Havelaar AH, Haagsma JA, Mangen MJ, Kemmeren JM, Verhoef LPB, Vijgen SMC, Wilson M, Friesema IHM, Kortbeek LM, van Duynhoven Y, van Pelt W (2012) Disease burden of foodborne pathogens in the Netherlands, 2009. Int J Food Microbiol 156(3):231-238

20. Hung HF, Kuo YM, Chien CC, Chen CC (2010) Use of floating balls for reducing bacterial aerosol emissions from aeration in wastewater treatment processes. J Hazard Mater 175(1):866-871

21. Jahne MA, Rogers SW, Holsen TM, Grimberg SJ (2015) Quantitative microbial risk assessment of bioaerosols from a manure application site. Aerobiologia 31(1):73-87

22. Kowalski M, Wolany J, Pastuszka JS, Plaza G, Wlazlo A, Ulfig K, Malina A (2017) Characteristics of airborne bacteria and fungi in some polish wastewater treatment plants. Int J Environ Sci Technol 14(10):2181-2192

23. Kozajda A, Jeżak K, Kapsa A (2019) Airborne Staphylococcus aureus in different environments-a review. Environ Sci Pollut Res 26(34):34741-34753

24. Li J, Zhou L, Zhang X, Xu C, Dong L, Yao M (2016) Bioaerosol emissions and detection of airborne antibiotic resistance genes from a wastewater treatment plant. Atmos Environ 124:404-412

25. Lim K, Hamilton AJ, Jiang SC (2015) Assessment of public health risk associated with viral contamination in harvested urban stormwater for domestic applications. Sci Total Environ 523:95108

26. Mark WL, Theodore JM, Jacqueline MG (2020) Protecting wastewater workers from disease risks: personal protective equipment guidelines. Water Environ Res 92:524-533

27. Masclaux FG, Hotz P, Gashi D, Savova-Bianchi D, Oppliger A (2014) Assessment of airborne virus contamination in wastewater treatment plants. Int J Environ Res 133:260-265

28. Niazi S, Hassanvand MS, Mahvi AH, Nabizadeh R, Alimohammadi M, Nabavi S, Mokamel A (2015) Assessment of bioaerosol contamination (bacteria and fungi) in the largest urban wastewater treatment plant in the Middle East. Environ Sci Pollut Res 22(20):16014-16021

29. Pascual L, Pérez-Luz S, Adela MY, Santamaría A, Gibert K, Salgot M, Apraiz D, Catalán V (2003) Bioaerosol emission from wastewater treatment plants. Aerobiologia 19(3-4):261-270

30. Rosenstock L (1995) 42 CFR part 84: Respiratory protective devices implications for tuberculosis protection. Infect Control Hosp Epidemiol 16:529-531

31. Saltelli A (2002) Sensitivity analysis for importance assessment. Risk Anal 22:579-590

32. Saltelli A, Aleksankina K, Becker W, Fennell P, Ferretti F, Holst N, Li S, Wu Q (2019) Why so many published sensitivity analyses are false: a systematic review of sensitivity analysis practices. Environ Model Softw 114:29-39 
33. Sánchez-Monedero MA, Aguilarb MI, Fenolla R, Roig A (2008) Effect of the aeration system on the levels of airborne microorganisms generated at wastewater treatment plants. Water Res 42:37393744

34. Seis W, Rouault P, Medema G (2020) Addressing and reducing parameter uncertainty in quantitative microbial risk assessment by incorporating external information via Bayesian hierarchical modeling. Water Res 185:116202-116209

35. Shi KW, Wang CW, Jiang SC (2018) Quantitative microbial risk assessment of greywater on-site reuse. Sci Total Environ 635:1507-1519

36. Singh NK, Sanghvi GY, Padhiyar H, Thanki A (2020) A state-of-the-art review on WWTP associated bioaerosols: microbial diversity, potential emission stages, dispersion factors, and control strategies. J Hazard Mater 15:124686

37. Stuart BO (1984) Deposition and clearance of inhaled particles. Environ Health Perspect 55:369-390

38. Teixeira JV, Miranda S, Monteiro RAR, Lopes FVS, Madureira J, Silva GV, Pestana N, Pinto E, Vilar VJP, Boaventura RAR (2013) Assessment of indoor airborne contamination in a wastewater treatment plant. Int J Environ Monit Assess 185(1):59-72

39. Thakur S, Sharma B, Verma A, Chaudhary J, Tamulevicius S, Thakur VK (2018) Recent progress in sodium alginate based sustainable hydrogels for environmental applications. J Clean Prod 198:143-159

40. Tian J, Yan C, Nasir ZA, Alcega SG, Tyrrel S, Coulon F (2020) Real time detection and characterisation of bioaerosol emissions from wastewater treatment plants. Sci Total Environ 721:137629

41. Uhrbrand K, Schultz AC, Koivisto AJ, Nielsen U, Madsen AM (2017) Assessment of airborne bacteria and noroviruses in air emission from a new highly-advanced hospital wastewater treatment plant. Water Res 112:110-119

42. Upadhyay N, Sun Q, Allen JO, Westerhoff P, Herckes P (2013) Characterization of aerosol emissions from wastewater aeration basins. J Air Waste Manage Assoc 63(1):20-26

43. Warren DW, Hairfield WM, Seaton D, Morr KE, Smith LR (1988) The relationship between nasal airway size and nasal-oral breathing. Am J Orthod Dentofac Orthop 93:289-293

44. Wang D, Wang J, Li Z, Zhao X (2018) Study on the exposure parameters of Chinese population. Proceedings of the 2018 Conference on Environmental and Health: Challenges for Interdisciplinary Cooperation. 2018:452-453

45. World Health Organization (2008) Guidelines for drinking-water quality: incorporating 1st And 2nd Addenda. 1. WHO Press, Switzerland

46. Xu P, Zhang C, Mou X, Wang XC (2020) Bioaerosol in a typical municipal wastewater treatment plant: concentration, size distribution, and health risk assessment. Water Sci Technol 82(8):1547-1559

47. Yang KX, Li L, Wang YJ, Xue S, Han YP, Liu JX (2019) Emission level, particle size and exposure risks of airborne bacteria from the oxidation ditch for seven months observation. Atmospheric Pollut Res 10(6):1803-1811 
48. Zhai Y, Li X, Wang T, Wang B, Li C, Zeng G (2018) A review on airborne microorganisms in particulate matters: composition, characteristics and influence factors. Environ Int 113:74-90

Figures

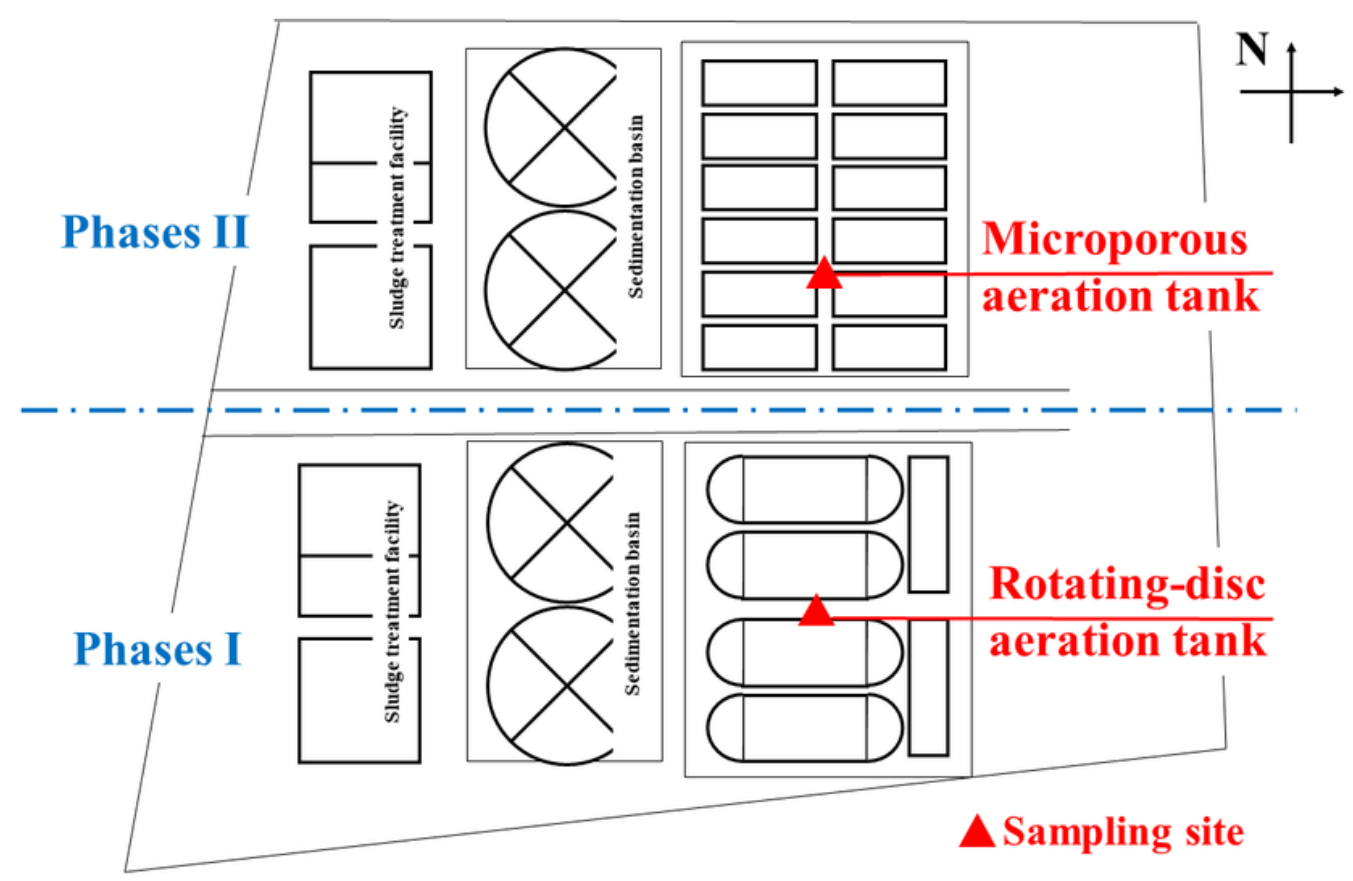

Figure 1

Layout plan of the wastewater treatment plant 


\section{Without personal protective equipment $\square$ With personal protective equipment}

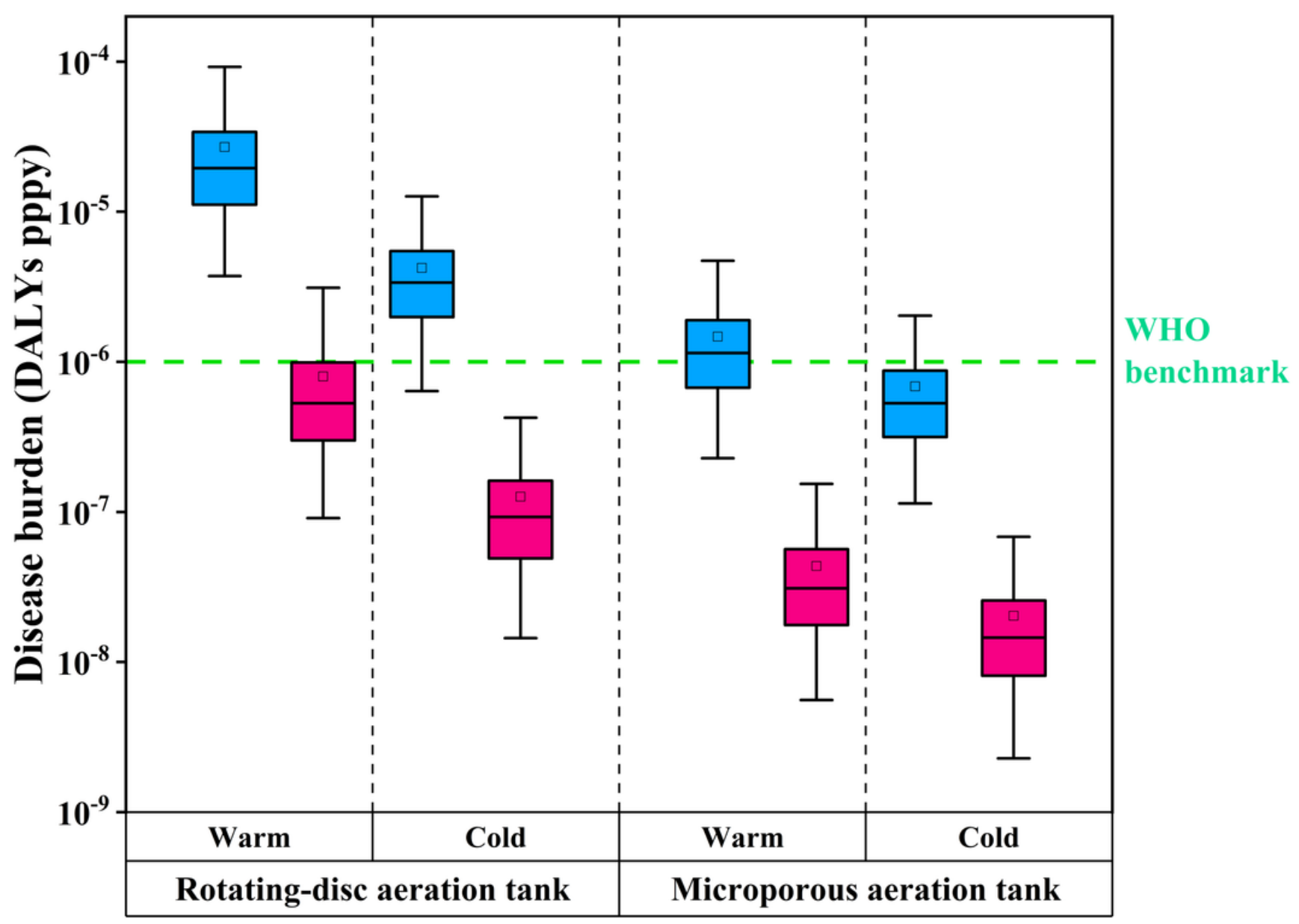

Figure 2

Box plot of the disease burden (DALYs pppy) of workers (with or without PPE) exposed to Staphylococcus aureus bioaerosol in the wastewater treatment plant in warm or cold period The bottom and top of the box represent the first and third quartiles (25th and 75th percentiles), respectively. The band inside the box denotes the second quartile (median), and the tetragon inside refers to the mean value (general condition). The whiskers show the 2.5th percentile (optimistic estimate at the best situation) and 97.5th percentile (conservative estimate at the worst situation) from each end of the box. WHO $=$ World Health Organization 

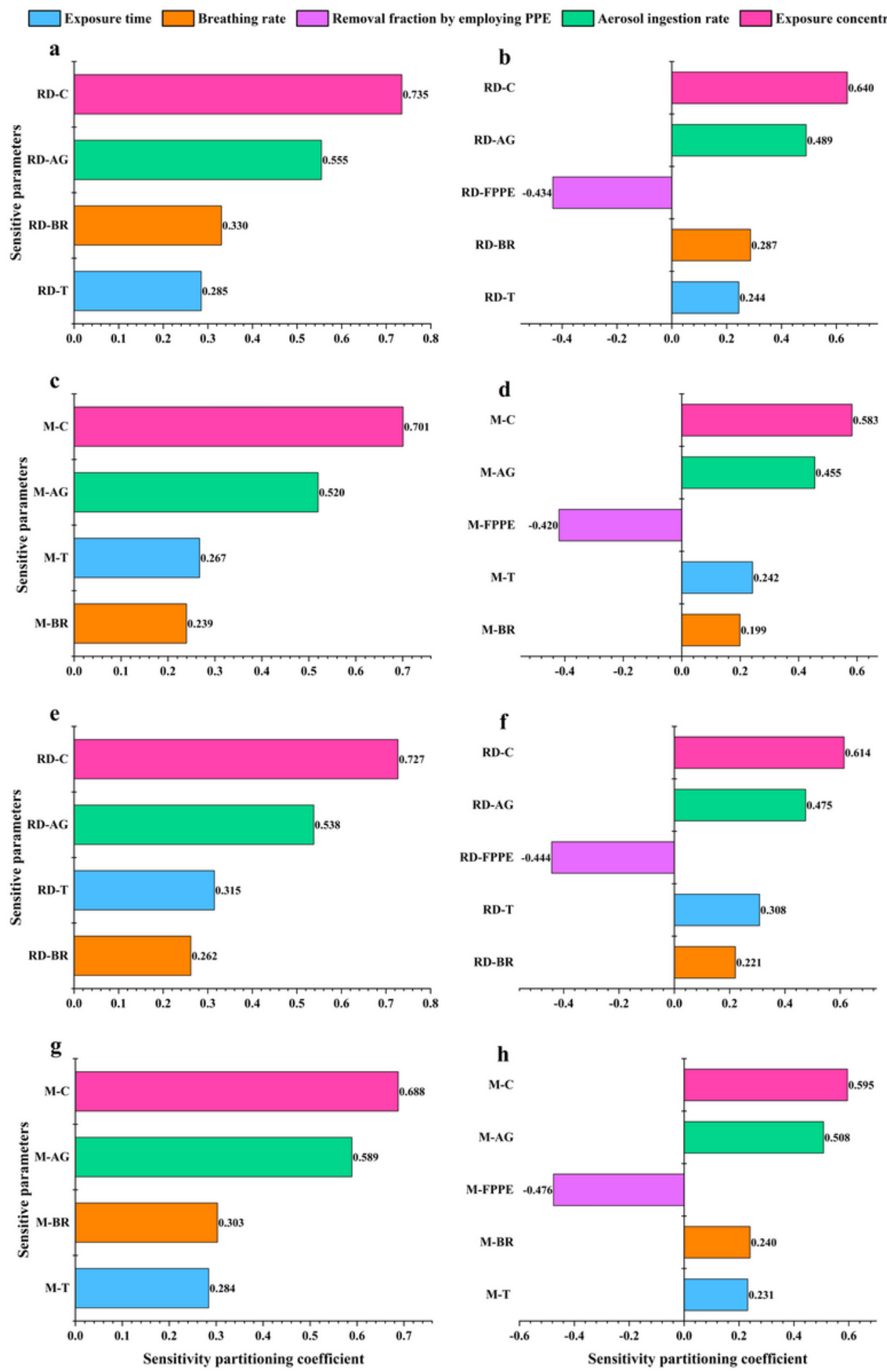

\section{Figure 3}

Tornado graphs of the ranking of sensitivity partitioning coefficient of input sensitivity parameters that affect the output value for workers exposed to Staphylococcus aureus bioaerosol in the wastewater treatment plant, referring to: (a) workers without PPE in rotating-disc aeration tank in warm period, (b) workers with PPE in rotating-disc aeration tank in warm period, (c) workers without PPE in microporous aeration tank in warm period, (d) workers with PPE in microporous aeration tank in warm period, (e) 
workers without PPE in rotating-disc aeration tank in cold period, and (f) workers with PPE in rotating-disc aeration tank in cold period, (g) workers without PPE in microporous aeration tank in cold period, and (h) workers with PPE in microporous aeration tank in cold period RD = Rotating-disc aeration tank $\mathrm{M}=$ Microporous aeration tank $\mathrm{C}=$ Exposure concentrations $\mathrm{T}=$ Exposure time $\mathrm{AG}=$ Aerosol ingestion rate $\mathrm{BR}$ $=$ Breathing rate FPPE $=$ Removal fraction by employing PPE PPE $=$ Personal protective equipment
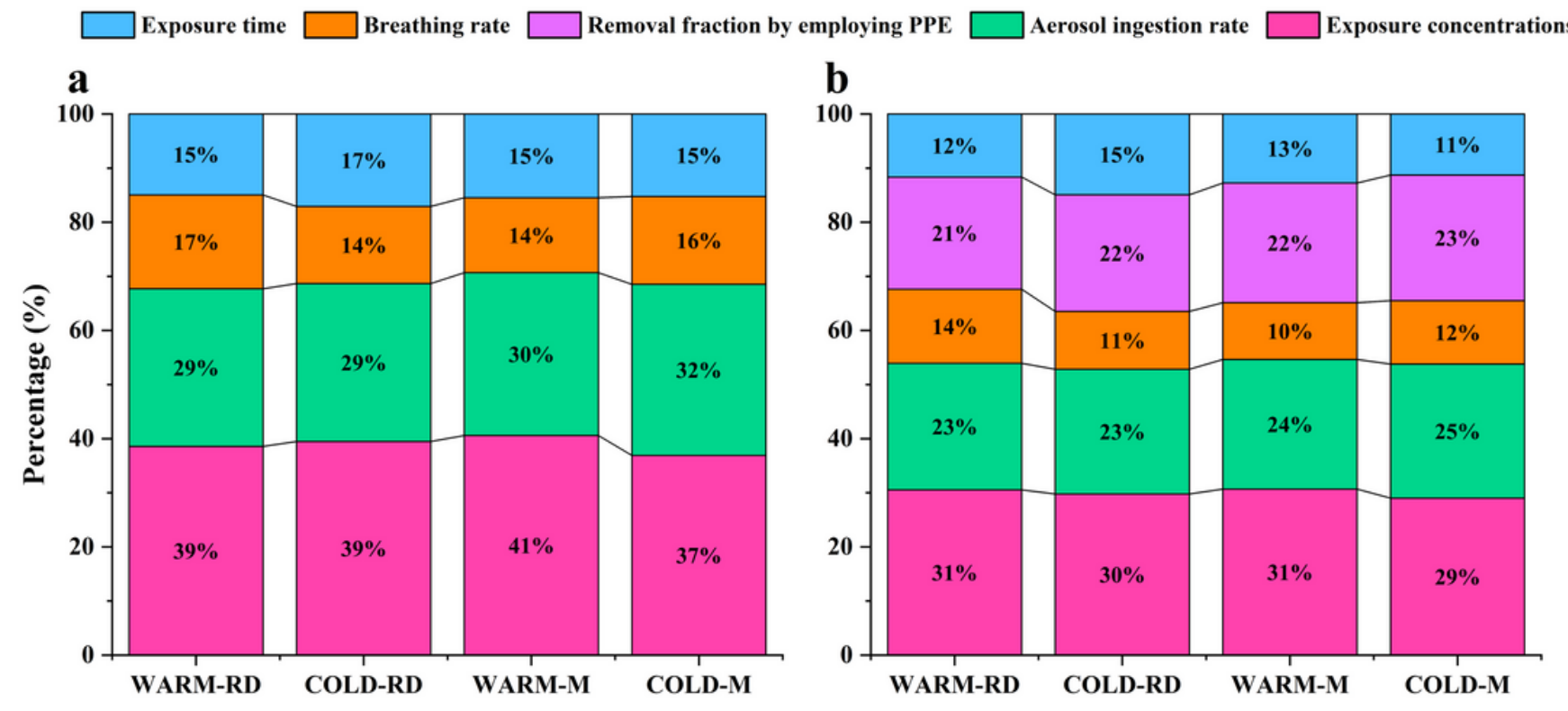

\section{Figure 4}

Percentage stack chart of the sensitivity percentage ratio of the sensitivity partitioning coefficient of each sensitivity parameter of disease burden for workers exposed to Staphylococcus aureus bioaerosol in the two aeration tanks of the wastewater treatment plant in warm or cold period, referring to: (a) workers without PPE, (b) workers with PPE Warm = Warm period Cold $=$ Cold period RD $=$ Rotating-disc aeration $\operatorname{tank} \mathrm{M}=$ Microporous aeration tank $\mathrm{C}=$ Exposure concentrations $\mathrm{T}=$ Exposure time $\mathrm{AG}=$ Aerosol ingestion rate $\mathrm{BR}=$ Breathing rate $\mathrm{FPPE}=$ Removal fraction by employing PPE PPE $=$ Personal protective equipment

\section{Supplementary Files}

This is a list of supplementary files associated with this preprint. Click to download.

- 20211029SupplementaryMaterial.docx 